\title{
Medievalista
}

Online

$30 \mid 2021$

Número 30

um estudo do simbolismo religioso da serpente em monumentos da

Era Viking (sécs. VIII-XI)Tese de Doutoramento em Ciências das

Religiões, apresentada ao Programa de Pós-Graduação em Ciências das Religiões (PPGCR), da Universidade Federal da Paraíba (UFPB), Brasil. Em junho de 2020. Orientação do Prof. Dr. Johnni Langer

\section{A guardiã dos mortos}

um estudo do simbolismo religioso da serpente em monumentos da Era Viking (sécs. VIII-XI). Tese de Doutoramento em Ciências das Religiões, apresentada ao Programa de Pós-Graduação em Ciências das Religiões (PPGCR), da Universidade Federal da Paraíba (UFPB), Brasil, em Junho de 2020. Orientação do Prof. Dr. Johnni Langer

\section{Leandro Vilar}

\section{OpenEdition}

Journals

\section{Edição electrónica}

URL: https://journals.openedition.org/medievalista/4568

DOI: $10.4000 /$ medievalista.4568

ISSN: 1646-740X

\section{Editora}

Instituto de Estudos Medievais - FCSH-UNL

\section{Refêrencia eletrónica}

Leandro Vilar, «A guardiã dos mortos», Medievalista [Online], 30 | 2021, posto online no dia 01 julho

2021, consultado o 24 julho 2021. URL: http://journals.openedition.org/medievalista/4568 ; DOI:

https://doi.org/10.4000/medievalista.4568

Este documento foi criado de forma automática no dia 24 julho 2021.

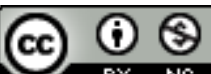

Mediavalista está licenciado com uma Licença Creative Commons - Atribuição-NãoComercial 4.0 Internacional. 
um estudo do simbolismo religioso da serpente em monumentos da

Era Viking (sécs. VIII-XI)Tese de Doutoramento em Ciências das

Religiões, apresentada ao Programa de Pós-Graduação em Ciências

das Religiões (PPGCR), da Universidade Federal da Paraíba (UFPB), Brasil. Em junho de 2020. Orientação do Prof. Dr. Johnni Langer

\section{A guardiã dos mortos}

um estudo do simbolismo religioso da serpente em monumentos da Era Viking (sécs. VIII-XI). Tese de Doutoramento em Ciências das Religiões, apresentada ao Programa de Pós-Graduação em Ciências das Religiões (PPGCR), da Universidade Federal da Paraíba (UFPB), Brasil, em Junho de 2020. Orientação do Prof. Dr. Johnni Langer

Leandro Vilar

\section{NOTA DO EDITOR}

Data recepção do artigo / Received for publication: 21 de Julho de 2020

1 O tema dessa tese é algo curioso como suscita o próprio título. Um estudo sobre duas coisas que normalmente causam espanto, ou pelo menos um certo receio ou desaprovação entre alguns. Falar sobre a morte e cobras não é algo para qualquer pessoa. E abordar ambos num estudo acadêmico é no mínimo peculiar. $O$ tema dessa tese de forma objetiva, foi estudar como os "vikings" dos séculos X e XI compreendiam o simbolismo da serpente associado a monumentos erguidos para fins memorialistas de honrar os vivos, mas também os mortos. Ou seja, um estudo sobre a crença na morte e como a cultura nórdica daquele tempo concebia o papel da serpente para isso.

2 Todavia, alguns podem suscitar o questionamento que o simbolismo da serpente não deveria gerar essa indagação, afinal as serpentes "seriam naturalmente" algo ruim, perigoso, profano e maléfico. Entretanto, a serpente está entre os animais simbolicamente mais emblemáticos devido a sua diversidade de simbolismos, o que a 
torna por excelência um bom exemplo para se explicar a polivalência e ambiguidade de significados que um símbolo pode possuir.

3 De fato, ainda hoje o senso comum tende a associar a imagem da serpente com essa visão negativa, mas isso não é uma unanimidade. $O$ historiador Jean Delumeau, em seu trabalho sobre a história do medo, observou que o medo não consistia apenas numa reação natural/biológica ao perigo, mas também era uma construção sociocultural, relacionada a valores, concepções de bravura e covardia, ideias, comportamentos, ideologias, crenças religiosas etc ${ }^{1}$. Por tal sentido, observamos que o medo de cobras não é apenas motivado por um fator biológico, mas também está carregado de um arcabouço simbólico de porquê devemos temer estes animais.

Embora, exista esse receio, desprezo e medo quanto à imagem das serpentes, entre algumas culturas estes animais eram vistos de forma positiva e até mesmo sagrada e divina. O biólogo Balaji D. Mundkur publicou The Cult of Serpent: An Interdisciplinar Survey of Its Manifestations and Origins, obra que se tornou uma referência nos estudos simbólicos acerca da serpente em diferentes culturas. Nesse livro, Mundkur procurou analisar o medo, o espanto, o fascínio e a veneração às serpentes através de distintos métodos como salienta o subtítulo de sua obra. Ele expressa que embora esses animais sejam criaturas estranhas, ainda assim, diferentes culturas apresentam incontáveis referências míticas, lendárias, folclóricas, literárias, artísticas, simbólicas e religiosas atribuídas a elas².

5 E partindo dessa percepção que o simbolismo da serpente é diverso e necessariamente não represente sempre algo negativo, propusemos esse estudo com o intuito de estudar a "religião dos vikings" a partir de seu simbolismo religioso contido na figura animal das serpentes presentes em monumentos da Era Viking. Nesse intuito, nossa pesquisa procurou analisar uma religião a partir de sua cultura material, visual e simbólica. Dessa forma, sublinhamos que estudar uma religião vai além da leitura de textos religiosos ou livros sagrados, do relato de ritos e crenças, da descrição de templos e locais de culto, do debate de dogmas e doutrinas ${ }^{3}$. Esse estudo também pode ser realizado através de aspectos da cultura material, imaterial, visual, das mentalidades, do imaginário, de comportamentos, da Estética, da Mitologia, da Psicologia, da Simbologia e de outras formas ${ }^{4}$.

Por tal condição, realizamos essa pesquisa na área das Ciências das Religiões ou Ciência da Religião, a qual consiste numa ciência social surgida na Europa do século XIX, sendo o termo cunhado pelo linguista, orientalista e mitólogo Max Müller (1823-1900). Na época, a partir de seus estudos e traduções de textos sagrados de religiões asiáticas, Müller desenvolveu um estudo comparado entre religiões e mitologia, vindo a originar a Ciência da Religião (Religionswissenschaft). A qual a partir do método comparado foi assimilando metodologias da Antropologia, História e Sociologia ainda no XIX, e no XX passou a englobar teorias e métodos de outras ciências. Seu objetivo central é estudar as mais diversas religiões e espiritualidades por um viés laico e científico, tratando a religião como um fenômeno não apenas tido como sagrado, mas como manifestação de aspectos socioculturais e históricos, determinados no tempo e espaço $0^{5}$.

Por tal conceito, nossa pesquisa inseriu-se nessa área através dos subcampos da História das Religiões, da Arqueologia das Religiões e da Simbologia Religiosa. Onde cada uma contribuiu teoricamente para o desenvolvimento desse estudo. E no caso do campo arqueológico, sublinhamos que trabalhamos com a subárea da chamada arqueologia da morte. Esta visa estudar os túmulos, tumbas, cemitérios, sepulturas, 
covas, objetos funerários, ritos fúnebres, mitos, lendas, costumes e tradições, os quais não apenas revelavam informações sobre a religião na qual tais práticas e crenças estão inseridas, mas também aspectos da sua sociedade e cultura, pois, entre distintos povos havia maneiras diferentes de sepultar ricos, pobres, governantes, criminosos, crianças, idosos, escravos etc. isso era reflexo de como aspectos socioculturais também estavam associados com as crenças religiosas ${ }^{6}$.

Mas, seria possível estudar uma religião pelo seu simbolismo animal? A partir da década de 1970, surgiu o chamado Estudos dos Animais (Animals Studies) e a Antrozoologia, uma subárea da Antropologia, especializada em estudar a relação entre a humanidade e o mundo animal ${ }^{7}$. Nessa perspectiva, o estudo dos animais procura identificar a importância das mais diferentes espécies, sejam elas domésticas ou silvestres, que desempenharam papel significativo no desenvolvimento social, civilizatório, político, econômico e cultural da humanidade ao longo da História ${ }^{8}$.

Pelo viés do estudos dos animais, optamos estudar o simbolismo religioso associado as serpentes para compreender as crenças referentes a chamada Religião Nórdica Antiga (Old Norse Religion) ou Religião escandinava pré-cristã (Pre-Christian Scandinavian Religion), os quais são conceitos acadêmicos para se referir ao conjunto de crenças nativas da Escandinávia que existiram durante a Antiguidade e o Medievo, antes de serem assimiladas e proibidas pelo Cristianismo, algo que teve início no século XI.

Nesse sentido, a Religião Nórdica Antiga tratava-se de uma religião de caráter politeísta, cotidiano, rural, fatalista, com aspectos xamânicos e mágicos, baseados principalmente em diferentes formas de cultos e ritos, o que envolvia sacrifícios de animais e até de humanos, para agradar ou pedir algo aos deuses. Não era uma religião institucionalizada, tampouco possuía dogma ou doutrinas reveladas por algum deus. Não existiam livros ou escritos com preceitos, ensinamentos ou normas. Foi uma religião que apresentava mudanças regionais, o que afetava a importância atribuída as divindades, e a forma como os cultos e ritos eram realizados?.

11 Por se tratar de uma religião sem textos sagrados e religiosos, mas por possuir uma rica iconografia, optamos em utilizar essas fontes iconográficas, algo que Sérgio da Mata assinalou que no estudo histórico das religiões, o historiador deva procurar estudar fontes que expressem as noções de sagrado, divino, profano, religioso, etc. como exemplo, os templos, os espaços de rito, culto, sacralidade e a própria iconografia. Tal condição é importante, pois o uso de imagens teve como função ser objeto de devoção, meio de persuasão ou de transmitir informação $0^{10}$.

Diante dessas prerrogativas, nós decidimos estudar a Religião Nórdica Antiga a partir de seu simbolismo animal, o qual é vasto, sendo encontrado na literatura, na linguagem, na iconografia, costumes e crenças ${ }^{11}$. E, por que seria relevante estudar o simbolismo da serpente para compreender essa religião? Sabemos que nos mitos esses animais possuem uma presença recorrente em determinadas narrativas contidas nas Eddas, mas o que se conhece do simbolismo ofídico fora dos mitos?

13 Na cultura material e visual na Escandinávia da Idade do Bronze Nórdica (1500-500 a.C.) até a Era Viking (sécs. VIII-XI), a presença de serpentes foi recorrente em pinturas, entalhes, gravações em objetos, e dentro dessa diversidade de fontes materiais, escolhemos trabalhar com dois tipos de monumentos. Os hogbacks e as pedras rúnicas.

Os hogbacks ${ }^{12}$ consistem em blocos de pedra com gravuras de animais, pessoas, signos, símbolos e ornamentação, construídos ao longo do século X e começo do XI, na 
Inglaterra e sul da Escócia, possuindo diferentes tipos de estilos (Fig. 1). Consistindo em monumentos que homenagiariam os vivos e os mortos, sendo fruto do período hiberno nórdico ou anglo-escandinavo, resultado da ocupação escandinava principalmente de origem dinamarquesa e norueguesa, em grande parte do atual território inglês, no que ficou conhecido como Danelaw ${ }^{13}$.

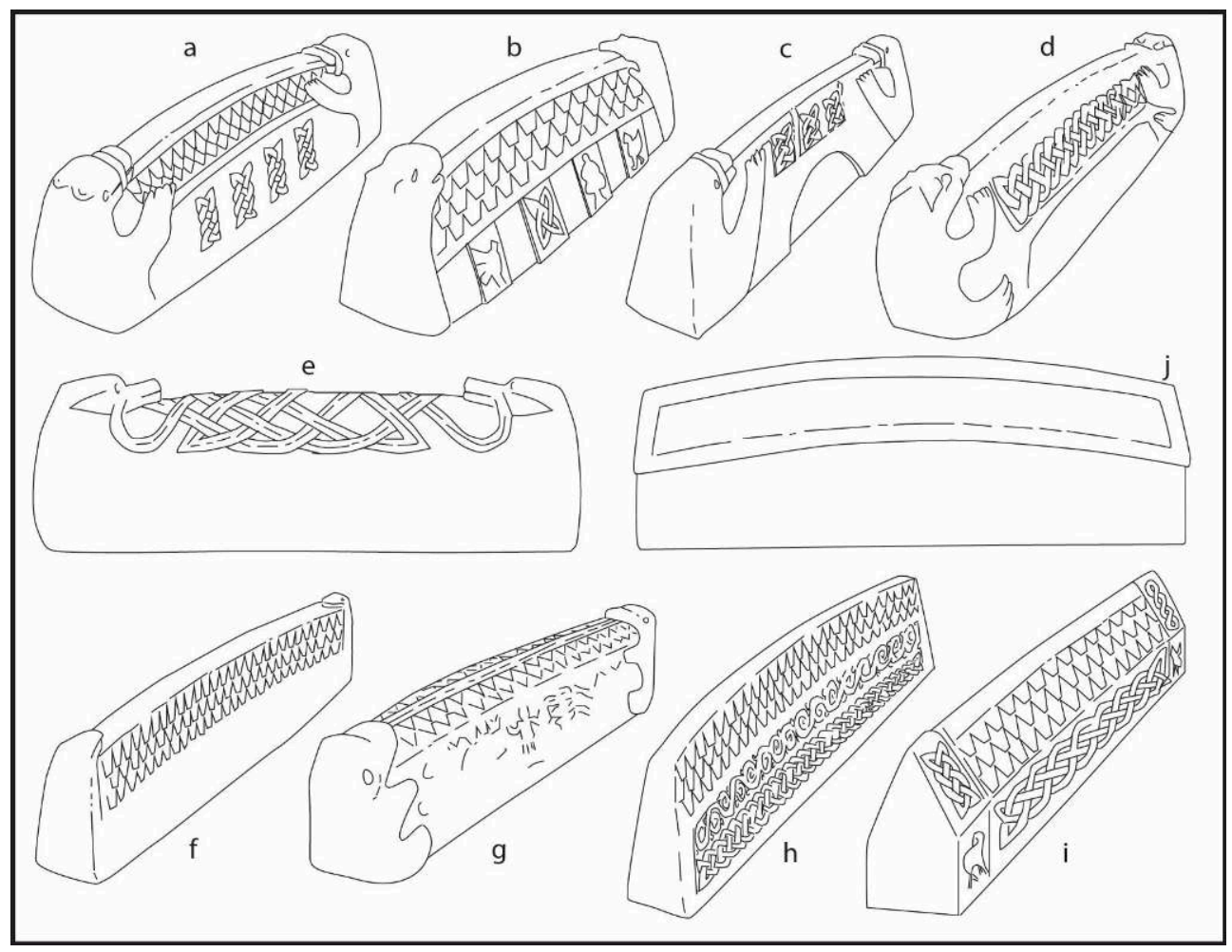

Fig. 1 - Os estilos de hogback, segundo James T. Lang

Fonte: WILLIAMS, Howard - "Hogbacks: the materiality of solid spaces" ..., p. 242

Quanto as pedras rúnicas (runestones), essas consistem em monumentos oriundos de influência germano-romana, surgidos na Suécia do século $\mathrm{V}$, e foram erguidos até o século XII. São pedras que inicialmente continham essencialmente apenas palavras escritas em runas do antigo futhark, posteriormente no século X, passou-se a usar o novo futhark e imagens de animais, pessoas, signos, símbolos e motivos ornamentais. Tais monumentos foram erigidos para fins memorialistas, principalmente para se honrar a memória dos mortos, algo bastante evidenciado ao longo do século XI, período no qual esse tipo de monumento proliferou na Escandinávia, principalmente na Suécia ${ }^{14}$.

Apesar de os hogbacks e as pedras rúnicas possuírem imagens de pessoas, animais, embarcações, escudos, armas, seres mitológicos, símbolos e signos, ainda assim, nesses dois tipos de monumentos foram detectados a presença de serpentes, e isso nos chamou a atenção, principalmente no caso das pedras rúnicas suecas, onde existem centenas de imagens destes animais, reflexo inclusive da arte nórdica, a qual fazia bastante uso de figuras animais para fins de decoração.

Lotte Hedeager ${ }^{15}$ e Bo Jensen ${ }^{16}$ salientam que a imagem de serpentes consista em um dos animais mais comuns presentes na arte escandinava da Antiguidade ao Medievo, suscitando várias interpretações do porquê essa criatura ser tão marcante entre os 
motivos artísticos. Apesar dessas várias indagações quanto aos significados que este animal apresentaria, ainda assim, não se tem certeza quanto aos seus sentidos.

David Wilson e Ole Klindt-Jensen sugeriram que as serpentes que formavam círculos em pedras rúnicas pudessem ser referências à serpente Jormungand, que nos mitos mordia a própria cauda, formando um ouroboros, símbolo cheio de significados, incluindo sentidos religiosos ${ }^{17}$. Signe Fuglesang cogitava que a serpente teria surgido como uma ornamentação, mas com o tempo ganhou valores simbólicos possivelmente associados com motivos religiosos e políticos. E nesse caso, a autora sugere possível influências cristãs para isso ${ }^{18}$.

Já Gro Mandt ${ }^{19}$ assinalava que as serpentes possuiriam um valor simbólico de nível social, econômico e religioso na cultura nórdica, apresentando inclusive ligação com a morte e a proteção, dois elementos que abordamos nesta tese. Brunning acredita que serpentes teriam um papel apotropaico, por isso aparecer em monumentos, armas, joias e outros tipos de objetos, partindo da analogia de que aquele animal perigoso, espantaria ameaças ${ }^{20}$.

Alain Marez apontou que deveria haver algum simbolismo para a presença daqueles animais nas pedras rúnicas. Embora o autor sugira que a serpente possa ser uma evolução das linhas de runas contidas em pedras mais antigas, ainda assim, ele não desconsidera a possibilidade de haver outros fins para além do motivo ornamental ${ }^{21}$. Victoria Thompson em seu estudo sobre hogbacks, destacou que a presença de serpentes em alguns desses monumentos poderia ter uma concepção religiosa, talvez de caráter fúnebre ${ }^{22}$. Robert Bailey e Rosemary Cramp assinalaram que serpentes eram representadas comumente na arte anglo-saxã para concepções distintas, incluindo valores religiosos ${ }^{23}$. Charlotte Ball comenta que na cultura anglo-saxã, dentro dos campos da Literatura, pintura e escultura, serpentes são bastante comuns e possuem significados distintos, o que inclui sentidos religiosos ${ }^{24}$.

21 Para conceder embasamento a essa indagação tornou-se necessário recorrer a outras fontes de estudo, oriundas da literatura, como relatos mitológicos e folclóricos, os quais apresentam elementos mágicos e religiosos aos quais as serpentes estavam associadas. Nesse sentido, nossos objetivos secundários requisitaram a necessidade de conhecer alguns dos principais simbolismos atribuídos as serpentes em âmbito geral e especificamente no contexto escandinavo; pensar a serpente como um animal associado a ideias apotropaicas e como tais caraterísticas poderiam ter se expressado em outros contextos. Assim como objetivamos também realizar uma catalogação, análise e quantificação das serpentes presentes em pedras rúnicas da Suécia. Com isso essa tese foi estruturada da seguinte forma:

No primeiro capítulo intitulado "O Simbolismo da Serpente", apresentamos os conceitos sobre símbolo, imagem e alguns teóricos para se estudar a cultura visual, dentre os quais Michel Pastoureau, Clifford Geertz e Umberto $\mathrm{Eco}^{25}$. Em seguida esboçou-se alguns dos principais simbolismos associados às serpentes no âmbito europeu, destacando a associação desse réptil com a vida e morte, cura e doença, proteção e ameaça, fecundidade e fertilidade, características essas que também estavam presentes na cultura nórdica da Era Viking. E com base nessas características, citamos varios exemplos contidos na Edda Poética (séc. XIII), Edda em Prosa (séc. XIII), em algumas sagas, além de relatos presentes em crónicas como o Gesta Danorum (séc. XII) e outros manuscritos ${ }^{26}$. 

fotografias de petróglifos, pedras gravadas de Gotland, broches, amuletos, monumentos etc. os quais contêm imagens ofídicas. E para encerrar este capítulo abordamos o mito da serpente do lar (tomt orm), crença que existiu entre vários povos do mundo, mas que se difundiu em partes da Suécia, e que poderia ter tido alguma relação com a grande presença de serpentes em pedras rúnicas, pois nessa crença, tais animais agiriam para fins de proteção, boa sorte, fertilidade e fecundidade ${ }^{27}$. primeira fonte de estudo advinda da cultura material, contextualizando historicamente a época em que esses monumentos foram erguidos, além de embasar teóricametodologicamente com estudiosos da História cultural, da Cultura visual e da Arqueologia. Nesse sentido, utilizamos o método de Panosfky ${ }^{28}$ para realizar a análise das imagens, mas recorrendo também a comentários de outros estudiosos como Burke, Mitchell, Joly e Schmitt ${ }^{29}$. E complementando o método panofskyano recorremos ao método arqueológico de Renfrew $^{30}$, pela condição de que analisamos não apenas imagens, mas os monumentos nas quais elas se encontram presentes (Fig. 2).

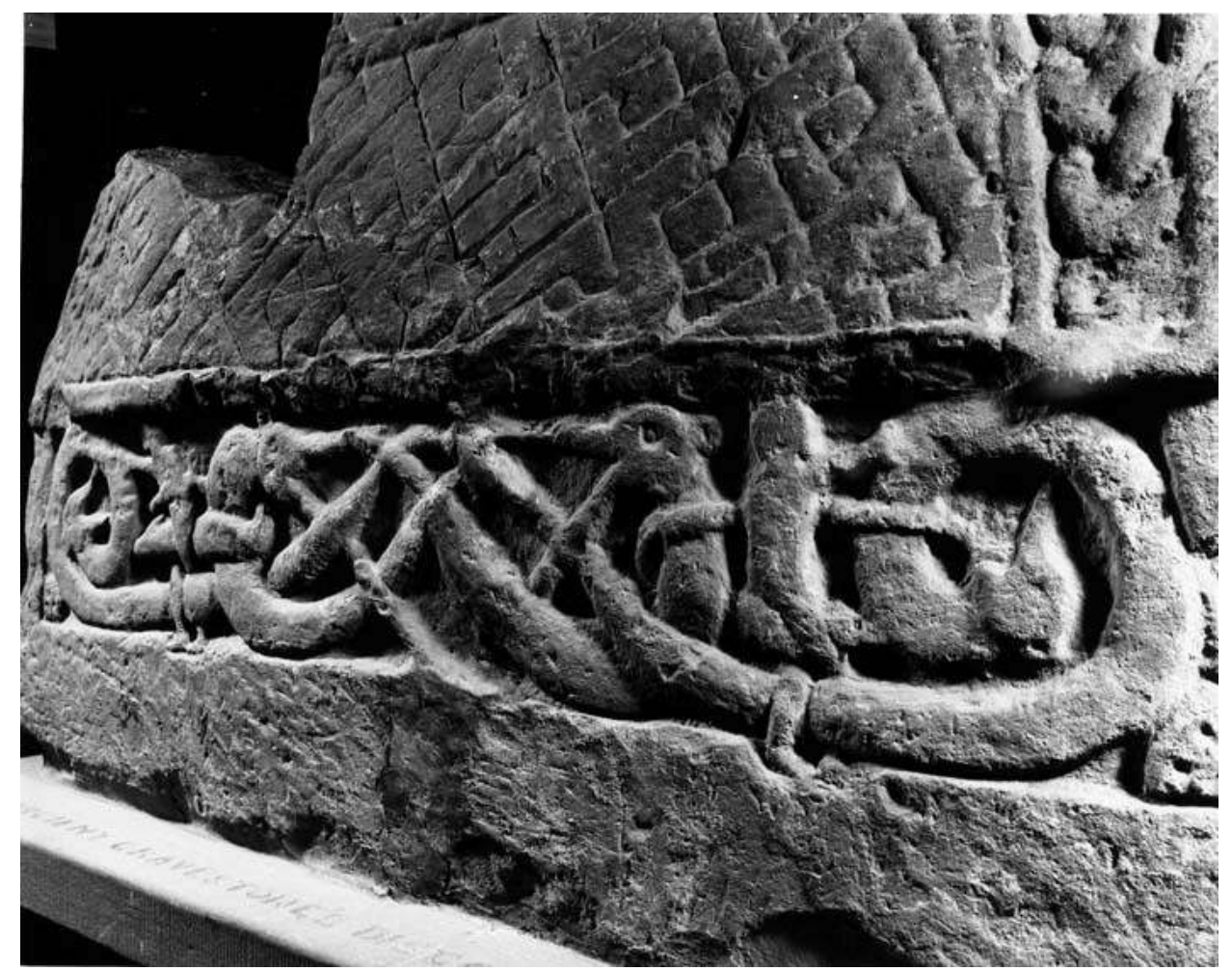

Fig. 2 - Detalhe do hogback Gosforth 05, apresentando duas pessoas abraçadas a serpentes. Igreja de Santa Maria em Gosforth, Inglaterra, séc. X. Esse foi um dos hogbacks analizados na tese.

Fonte: HTTP://WWW.ASCORPUS.AC.UK/CATINDEX.PHP

No terceiro capítulo, intitulado "Pedras Rúnicas Suecas", realizamos uma breve introdução sobre esse tipo de monumento. Em seguida através de um procedimento quantitativo, identificamos em cada província sueca a quantidade de pedras rúnicas contendo imagens de serpentes. Nessa seção apresentamos comentários gerais sobre 14 províncias durante a Era Viking, contextualizando o período histórico de surgimento destes monumentos, complementando tais dados com 16 gráficos por nós elaborados, os quais quantificaram mais de 1.500 pedras rúnicas analisadas. Salientando que na Suécia a estimativa é que se conheçam 2.500 exemplares desses monumentos, o que 
significa que mais da metade possui serpentes. Dado que corrobora como este animal foi um tema comum e importante naquela cultura. Neste capítulo realizamos um dos objetivos secundários que foi quantificar as pedras rúnicas com serpentes.

Por fim, no último capítulo da tese, intitulado "O simbolismo ofídico em pedras rúnicas", realizamos a segunda parte do nosso objetivo geral, dessa vez elencando algumas pedras rúnicas pelas quais analisamos o simbolismo da serpente (Fig. 3). Neste caso, essa análise foi dividida em dois momentos: num primeiro que abarca o início do capítulo, objetivamos analisar as formas geométricas das serpentes rúnicas a fim de identificar modelos e estilos, e a possibilidade de que tais formas poderiam conter sentidos simbólicos também. Aqui recorremos a conceito de schemata de Gombrich para interpretar esses dados ${ }^{31}$.

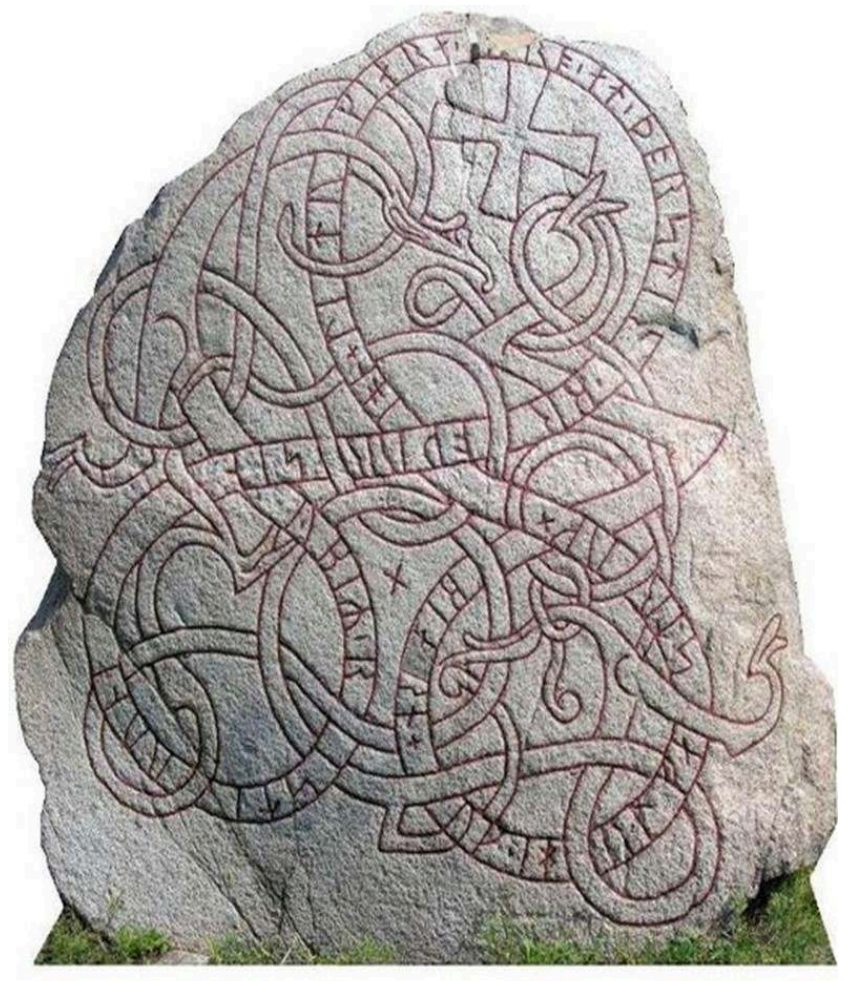

Fig. 3 - A pedra rúnica U 279, classificada no estilo Pr4 (1070-1100). Uppland, Suécia. Esse monumento foi um dos exemplares analisado na tese.

FONTE: https://www.schleugerhard.com/.

27 Já na segunda parte do capítulo realizamos análises específicas do simbolismo da serpente em alguns estudos de caso, trabalhando com exemplos de cada um dos estilos de serpente rúnica existentes de acordo com a classificação de Gräslund, a qual definiu que tal elemento iconográfico passou por seis estilos (B-e-v, Pr1, Pr2, Pr3, Pr4 e Pr5) entre os anos 1000 e 1150. Nesse ponto, optamos em analisar cada um destes estilos por eles conterem elementos simbólicos particulares como a presença de círculos, nós, anéis, espirais, além de retratar em alguns casos, serpentes com chifres, orelhas, patas e $\operatorname{asas}^{32}$.

28 Ao longo de 272 páginas, 51 imagens, 16 gráficos e 2 tabelas, realizamos as análises dos hogbacks e das pedras rúnicas, e a pesquisa alcançou resultados positivos, interessantes e alguns até inicialmente não considerados nas primeiras hipóteses, ainda nos idos da investigação. Dessa forma, podemos confirmar a existência de significados religiosos 
presentes no simbolismo da serpente na Era Viking, algo inclusive adotado por nórdicos cristianizados, condição bem visível no contexto das pedras rúnicas, onde nestes monumentos encontram-se a presença de símbolos cristãos como a cruz e a árvore da vida, além de menções ao nome de Deus, Maria, Jesus, e de alguns santos e anjos, os quais aparecem em epitáfios, sendo solicitado que estes protegessem a alma do falecido. Por tal aspecto, observa-se que a serpente necessariamente não seria associada nesse contexto com a figura do Diabo.

Nesse ponto, além de confirmar um simbolismo religioso associado a serpente, se fez necessário determinar quais aspectos religiosos seriam esses. Dentre as conclusões alcançadas, estão que a serpente estaria associada a vida, a morte, a ressurreição (no caso dos cristãos) e a proteção. E como sublinhado anteriormente, a crença na serpente do lar já atribuía essa função para esse animal, além de que o uso de cobras para proteger lugares da vida ou da morte, é encontrada entre outros povos. E no caso dos nórdicos da Era Viking, tal condição também foi observada por nós.

Nesse sentido, as serpentes surgiriam nestes monumentos, principalmente nas pedras rúnicas, atuando como símbolos apotropaicos, partindo do pensamento analógico medieval ${ }^{33}$, no qual se usaria símbolos para se espantar ameaças, com isso, uma serpente que evoca a ideia de ameaça, seria usada para se espantar outras ameaças. Por tal condição elas agiriam como "guardiãs dos mortos", agindo de alguma forma para manter afastado perigos que pudessem causar algum problema a alma do falecido, interrompendo sua viagem aos mundos dos mortos, ou deixando-o aprisionado no mundo dos vivos. Sobre isso, constatou-se também que as pedras rúnicas segundo alguns estudiosos, teriam uma função de auxiliar as almas a encontrar seu destino, agindo como "pontes" ou "caminhos", e as serpentes seriam as responsáveis por vigiar tais estradas.

\section{NOTAS}

1. Conferir a introdução de DELUMEAU, Jean - A história do medo no Ocidente: 1300-1800. Tradução de Maria Lúcia Machado e Heloísa Jahn. São Paulo: Companhia de Bolso, 2009.

2. MUNDKUR, Balaji D. - The Cult of Serpent: An Interdisciplinary Survey of Its Manifestations and Origins. Albany: University New York Press, 1983.

3. BRELICH, Angelo - Introduzione alla storia delle religioni. Roma: Edizioni dell'Ateneo, 1966.

4. WACH, Joachim - Introduction to history of religions. New York: Macmillan Publishing Company, 1988.

5. USARSKI, Frank - "História da Ciência da Religião". in PASSOS, João Décio; USARSKI, Frank Compêndio da Ciência da Religião. São Paulo: Paulus/Paulinas, 2013, pp. 51-61.

6. PEARSON, Mike Parker - Archaeology of death and burial. Texas: Texas University Press, 1999.

7. KALOFF, Linda - Looking at Animals in Human History. London: Reaktion Books, 2007.

8. DEMELLO, Margo - Animals and Society: an introduction to Human-Animal Studies. New York: Columbia University Press, 2012.

9. LANGER, Johnni - "Vikings". in FUNARI, Pedro Paulo (org.) - As religiões que o mundo esqueceu. São Paulo: Contexto, 2009, pp. 130-143. 
10. MATA, Sérgio da - História \& Religião. Belo Horizonte: Autêntica Editora, 2010.

11. JENNBERT, Kristina - Animals and humans: recurrent symbiosis in archaeology and old Norse religion. Lund: Nordic Academy Press, 2011 (Vägar Till Midgård, 14).

12. Sobre os hogbacks, conferir os estudos de: LANG, James $\mathrm{T}$ - "Hogback monuments in Scotland". in Proceedings of the Society of Antiquaries of Scotland, n. 105, 1972, pp. 206-235. WILLIAMS, Howard - "Hogbacks: the materiality of solid spaces". in WILLIAMS, Howard; KIRTON, J; GONDEK, M (eds.) - Early Medieval Stone Monuments: materiality, biography, landscape. Woodbridge: Boydell and Brewer, 2015, pp. 241-268.

13. O Danelaw (lei dos daneses) foi um termo de origem inglesa, surgido no século XI, para denominar os territórios anglo-saxões da Nórtumbria, Mércia e Anglia Oriental, ocupados por reis e chefes nórdicos, principalmente de origem dinamarquesa e norueguesa. O Danelaw foi uma região de fronteiras móveis e governado por vários governantes, sendo ocupado entre 867 e 954, quando entrou em declínio. No entanto, décadas depois, o rei Sueno I da Dinamarca, nos anos 1000 , voltou a conquistar terras na Inglaterra, recuperando o controle nórdico.

14. JANSSON, Sven B. F - Runes in Sweden. Translation by Peter Foote. 2. ed. Värnamo: Gidlunds/ Royal Academy of Letters, History and Antiquities, 1987.

15. HEDEAGER, Lotte - Iron Age Myth and Materiality: an archaeology of Scandinavia AD 400-1000. London: Routledge, 2011.

16. JENSEN, Bo - "Chronospecificities: period-specific ideas about animals in Viking Age Scandinavian Culture". Society \& Animals 21 (2013), pp. 208-221.

17. WILSON, David M; KLINDT-JENSEN, Ole - Viking Art. New York: Cornell University Press, 1966. Apesar de ser um livro referência no estudo artístico sobre a arte viking, o livro já apresenta algumas interpretações desatualizadas, sobretudo referente a alguns tipos de símbolos.

18. FUGLESANG, Signe Horn - "Swedish Runestones of the Eleventh Century: Ornament and Dating”. in NOWAK, Sean; DÜWEL, Klaus (eds.) - Runeninschriften als Quellen interdisziplinärer Forschung Unauthenticated. Berlin/New York: Walter de Gruyter, 1998, pp. 197-218.

19. MANDT, Gro - "Fragments of Ancient Beliefs: The Snake as a Multivocal Symbol in Nordic Symbolism". ReVision 23/1 (2000), pp. 17-23.

20. BRUNNING, Sue - “'(Swinger of) the Serpente of Wounds': swords and snakes in the Viking Mind”. in BINTLEY; Michael D. J; WILLIAMS, Thomas J. T (eds.) - Representing beasts in early Medieval England and Scandinavia. Anglo-Saxon Studies 29. Woodbrige: The Boydell Press, 2015, pp. 53-70.

21. MAREZ, Alain - Anthologie Runique. Paris: Les Belles Lettres, 2007 (Classiques du Nord). Apesar de o autor realizar um amplo estudo sobre as pedras rúnicas, ele pouco abordou o simbolismo presente nelas, por isso dizer que talvez não tivessem apenas um sentido ornamental.

22. THOMPSON, Victoria - Dying and Death in Later Anglo-saxon glanden. Woodbridge: The Boydell Press, 2004.

23. BAILEY, Robert; CRAMP, Rosemary (orgs.) - The Corpus of Anglo Saxon Stone Sculpture. Volume II. Cumberland, Westmorland and Lancashire-North-of-the-Sands. Oxford: Oxford University Press, 1988. O trabalho dos dois é referência ainda hoje nos estudos sobre hogbacks e outros monumentos de pedra anglo-saxão. Entretanto, algumas interpretações simbólicas já estão defasadas ou são postas em contestação.

24. BALL, Charlotte Elizabeth - 'A creeping thing': the motif of the Serpent in Anglo-Saxon England. Leicester: University of Leicester, 2017. Tese de Doutoramento. Dentre algumas conclusões apresentadas pela autora estão de que as serpentes nesse contexto significariam: perigo, medo, provação, morte, doença, cura, pecado, tentação, etc. A autora observou influências pagãs e cristãs nos simbolismos dados a serpente.

25. Sobre o conceito de símbolo, utilizamos os seguintes autores: PASTOUREAU, Michel "Símbolo". in LE GOFF, Jacques; SCHMITT, Jean-Claude (orgs.) - Dicionário temático do Ocidente medieval. São Paulo: EDUSC, 2002, pp. 485-510. GEERTZ, Clifford - A interpretação das culturas. Rio 
de Janeiro: LTC, 2008. ECO, Umberto - Arte e Beleza na estética medieval. Tradução de Mário Sabino. Rio de Janeiro: Editora Record, 2010.

26. A Edda Poética e a Edda em Prosa são as principais fontes sobre a mitologia nórdica, tendo sido escritas no século XIII, na Islândia. Em língua portuguesa não há traduções integrais e diretas da língua original. Com isso, utilizamos edições em língua espanhola, especialmente as de Luís Lerate, e em língua inglesa utilizamos a edição da Poetic Edda de Carolyne Larrigton e a Uppsala Edda de Anthony Faulkes. Já as sagas há algumas traduzidas para o português e publicadas no Brasil. Quanto ao Gesta Danorum, também não existe uma tradução para o português, então recorremos a tradução inglesa de Peter Fisher.

27. LECOUTEUX, Claude - The tradition of household spirits: ancestral lore and practices. Translated by Jon E. Graham. Vermont: Inner Traditions, 2013.

28. Usamos dois livros do autor: PANOFSKY, Erwin - El significado en las artes visuais. Madrid: Alianza Editorial, S. A., 1979. E PANOSFKY, Erwin - Studies in Iconology: humanistic themes in the art of Renaissance. Colorado: Westview Press, 1972. Embora o método panosfykiano seja ainda bastante atualizado, ele já foi criticado por distintos autores, quanto a alguns problemas de aplicação. Por isso utilizamos outros autores para poder solucionar esses problemas metodológicos.

29. Outros autores que estudam imagem, arte, iconografia, os quais recorremos nesta tese, foram: BURKE, Peter - Testemunha ocular: história e imagem. Tradução de Vera Maria Xavier dos Santos. Bauru: EDUSC, 2004 (Coleção História), JOLY, Martine - Introdução à análise da imagem. Lisboa: Edições 70, 2007, MITCHELL, William J. T - What do pictures want? The lives and the loves images. Chicago: Chicago University Press, 2005. SCHMITT, Jean-Claude - O corpo das imagens: ensaios sobre a cultura visual na Idade Média. Tradução de José Rivair Macedo. Bauru: EDUSC, 2007.

30. RENFREW, Colin; BAHN, Paul - Archaeology, theories, methods, and pratices. 6. ed. London: Thames e Hudson, 2012.

31. GOMBRICH, Ernst H - Arte e Ilusão. Tradução de Raul de Sá Barbosa. São Paulo: Martins Fontes, 1995.

32. GRÄSLUND, Anne-Sofie - "Dating the Swedish Viking-Age rune stones on stylistic grounds". in STOKLUND, Marie; et. al. (eds.) - Runes and their Secret. Studys in Runology. Copenhagen: Museum Tusculanum Press, 2006, pp. 117-139.

33. Sobre o pensamento analógico medieval, recomendamos a leitura destes dois artigos: FRANCO JÚNIOR, Hilário - "Modelo e Imagem. O pensamento analógico medieval". Bulletin du Centre d'Études Médiévales d'Auxerre | BUCEMA 2 (2008), pp. 1-29. FRANCO JÚNIOR, Hilário - "Similibus simile cognoscitur. O pensamento analógico medieval". Medievalista on-line [Em linha] 14 (jul/dez 2013) [Consultado a 10 julho 2020]. Disponível em https://medievalista.iem.fcsh.unl.pt/ index.php/medievalista/article/view/248/237.

\section{AUTOR}

\section{LEANDRO VILAR}

Centro de Educação - Programa de Pós-Graduação em Ciências das Religiões, Universidade Federal da Paraíba, 58031-220 João Pessoa, Brasil . vilarleandro@hotmail.com. https://orcid.org/ 0000-0001-8905-9727 